\title{
Antonio Candido, Antonio Cornejo Polar E A CONSTITUIÇÃO DE UM PENSAMENTO LATINO-AMERICANISTA ${ }^{1}$
}

\author{
Débora Cota \\ deboracota.lit@gmail.com
}

As Jornadas de Literatura Latino-americana organizadas pelo Instituto de Estudos da Linguagem (IEL) da Universidade Estadual de Campinas (Unicamp), em 1980, reuniram no Brasil um dos mais importantes grupos de críticos latino-americanos daquele momento; entre eles, encontravam-se Antonio Candido, idealizador do evento, Ángel Rama e Antonio Cornejo Polar. Conforme Beatriz Sarlo (1980), os participantes reuniam-se para debater a integração ou marginalidade da literatura brasileira com relação às demais latino-americanas; a diversidade ou unidade literária na América Latina; e a crítica e seus métodos frente à produção literária da região. Estas seriam, em suma, as preocupações que aproximavam críticos de diferentes partes do continente e que dedicaram a essas questões, durante décadas, todo o seu trabalho.

Mas as Jornadas de Literatura Latino-americana não eram a primeira atividade na qual se debatiam esses temas, muito menos a que se propunha a reunir pesquisadores de diversas regiões. Este afã integracionista também se encontrava disseminado em revistas como a brasileira Argumento (1973-1974), dirigida por Antonio Candido, ou a

\footnotetext{
${ }^{1}$ Pesquisa realizada com o apoio do CNPq.
} 
uruguaia Marcha (1939-1974), dirigida por, entre outros nomes, Ángel Rama, bem como a peruana Revista de Crítica Literaria Latinoamericana, organizada por Antonio Cornejo Polar.

Muitos dos presentes nas Jornadas também voltariam a se encontrar em 1982, na Universidad Simón Bolívar, em Caracas, e em 1983, novamente na Unicamp, em eventos sobre a constituição de uma história da literatura latino-americana e que culminaram na publicação, nos anos 1990, dos três volumes de América Latina: palavra, literatura e cultura, organizados por Ana Pizarro. São ainda projetos com claro propósito integracionista a Biblioteca Ayacucho (1974), na Venezuela, e a Casa de las Américas (1959), em Cuba.

Para Nelson Osorio Tejeda (2013), antes da década de 196o, já existiam críticos literários e pesquisadores, como Pedro Henríquez Ureña,

pero que no constituían un conjunto que diseñara un perfil o un proyecto crítico-literario que fuera expresión de una conciencia latinoamericana específica y diferenciada. En otras palabras, había críticos latinoamericanos, pero no "una crítica latinoamericana” propiamente tal (OSORIO TEJEDA, 2013, p. 12).

Esse perfil ou projeto crítico, desenhado desde a década de 1960, está baseado, especialmente, na visão em conjunto da região, nas afinidades históricas, sociais e culturais. E a adoção, nesse momento, da expressão "literatura latino-americana", amplamente discutida, uma vez que não consegue designar necessariamente as especificidades locais, está relacionada, entre outros fatores, à oficialização da expressão "Latinoamérica", com o surgimento de organismos internacionais, em meados do século XX, como a CEPAL e a CLACSO, por exemplo. América Latina, nesses termos, funciona como um dispositivo (AGAMBEN, 2009) que cria políticas, processos de subjetivação, redes de pesquisa, de "amizades" e instituições. Nesse caso, o "dispositivo América Latina" abarca o projeto de constituição do que aqui se chama um "pensamento latino-americanista”: teoria, crítica e história literárias, discutido por esse grupo de pesquisadores a que Tejeda se refere como "crítica latino-americana".

Pretende-se aqui destacar, entre todas essas atividades de cunho integracionista, a aproximação que ocorre durante esses eventos e projetos realizados na década de 1970 e início dos anos 1980, entre dois dos mais importantes críticos participantes: Antonio Candido e Antonio Cornejo Polar. Seria também uma aproximação entre o pensamento andino e o brasileiro? Há nesse período um maior contato entre esses dois críticos 
seja pelas atividades já citadas, seja mediante as visitas de Antonio Candido à Universidad Nacional Mayor de San Marcos para ministrar conferências (1976), ou ainda sua colaboração na Revista de Crítica Literaria Latinoamericana, organizada por Cornejo Polar, no Peru, desde 1973. ${ }^{2}$ Salienta-se, contudo, as dificuldades da difusão das ideias desses intelectuais nas regiões em questão, uma vez que a produção crítica de Antonio Candido começa a ser efetivamente traduzida ao espanhol somente a partir do início dos anos 1990. Enquanto que de Cornejo Polar existe em português apenas a coletânea de ensaios $O$ condor voa: literatura e cultura latino-americanas, organizada por Mario Valdés, e publicada, em 200o, pela editora da Universidade Federal de Minas Gerais (UFMG).

Mas, o encontro e o mútuo conhecimento implicam, no caso dos dois críticos, na construção de um pensamento comum? Em que termos há uma aproximação entre seus pensamentos? Parte-se da consideração de um tema da teoria literária de caráter metodológico ou "metacrítico": a categoria de sistema literário como uma categoria central nos debates em torno da literatura latino-americana por essa rede de pesquisadores. $\mathrm{O}$ estudo desse conceito, a participação de Antonio Candido na Revista de Crítica Literaria Latinoamericana e os registros da reunião em Caracas (1982), para a constituição de uma história da literatura latino-americana, nos servem aqui como chave de leitura do contato entre a produção crítica de Antonio Candido e Antonio Cornejo Polar.

A Formação da literatura brasileira, de Antonio Candido, foi publicada em dois volumes, em 1959, que exploram, respectivamente, o arcadismo e o período romântico brasileiro. Estes são tomados como períodos formativos da literatura do país explicados a partir de uma metodologia claramente desenhada na Introdução da obra e também comentada no prefácio da segunda edição. Aliás, nesse caso, é preciso dizer que esses textos, Introdução e Prefácio, concorrem com o desenvolvimento da obra quanto ao fato de serem "mais conhecidos", uma vez que suscitaram uma série de debates. Trata-se de mostrar historicamente duas fases constitutivas, mas não definitivas, da literatura nacional, ou seja, procura-se evidenciar a configuração da literatura brasileira através de um processo evolutivo,

${ }^{2}$ As colaborações do crítico brasileiro na Revista de Crítica Literaria Latinoamericana começam a aparecer somente a partir de 1981. Em 1973, Antonio Candido também lançou, no Brasil, a revista de cultura Argumento, voltada para as questões culturais da América Latina e radicalmente encerrada pela ditadura militar em 1974, em seu quarto número. Antonio Cornejo Polar não colaborou nessa revista. 
mas que seguirá, como se verá adiante, em outros momentos históricos. Estrutura a tese da Formação a ideia de que, para haver uma literatura nacional, esta deve dar forma a um sistema no qual há:

a existência de um conjunto de produtores literários, mais ou menos conscientes do seu papel; um conjunto de receptores, formando os diferentes tipos de público, sem os quais a obra não vive; um mecanismo transmissor, (de modo geral, uma linguagem, traduzida em estilos), que liga uns a outros (CANDIDO, 1997, p. 23).

Com a efetiva concretização do sistema que coloca em movimento e relaciona os elementos da tríade autor/obra/público, o crítico prevê outro fenômeno essencial na constituição da literatura: "a formação da continuidade literária”, ou seja, a formação de uma tradição que ocorre por intermédio da transmissão de elementos que devem ser considerados, aceitos ou não, para que se tenha uma literatura.

O sistema segue o modelo estrutural de comunicação desenvolvido pelo formalismo em voga naquele momento, porém, considera "as condições materiais de sua realização", rechaçando a leitura de obras que as reduzia a problemas de linguagem. Desse modo, no Arcadismo brasileiro, por exemplo, não deixa de destacar a relação da tríade mineira - Cláudio Manoel da Costa, Tomás Antônio Gonzaga e Alvarenga Peixoto - com a Inconfidência Mineira. E, no Romantismo, demonstra o quanto a literatura, impulsionada pelos ideais da Revolução Francesa e pelo momento da Independência, desenvolverá os ideais nacionais.

É também importante para a compreensão do sistema literário brasileiro a noção de "empenho" da literatura na construção da nação. Segundo Candido, o projeto de construir uma literatura independente da de Portugal também foi o de construir uma nação. O crítico explica que com "empenho" não quer dizer que a literatura "seja social ou deseje tomar partido ideologicamente"; ele pretende apenas mostrar que a literatura "é toda voltada, no intuito dos escritores ou na opinião dos críticos, para a construção duma cultura válida no país. Quem escreve, contribui e se inscreve num processo histórico de elaboração nacional", afirma (1997, p. 17).

O mais emblemático texto do crítico brasileiro que analisa desde tal perspectiva a produção literária latino-americana é "Literatura e subdesenvolvimento", publicado pela primeira vez em 1970. Trata-se do mais conhecido trabalho de Candido entre os estudiosos hispano-americanos, fruto de outro projeto desenvolvido sob o "dispositivo 
América Latina", financiado pela Unesco e liderado por César Fernández Moreno: América Latina en su literatura (1972). Nele, Candido se dedica à literatura continental a partir do período romântico, isto é, demonstra não estar acabado aquele processo descrito na Formação. O trajeto que demarca até os anos 1960 é uma linha evolucionista que culmina na tradição regionalista que expõe semelhanças entre as literaturas latino-americanas, excetuando alguns casos. Aqui o emprego da dialética que leva à consideração do contexto, e do social, além do claro manuseio da teoria da dependência correm junto com a abordagem via sistema literário. A expressão da consciência do atraso, da dependência econômica da região nessas produções, balizaria as várias fases dessa literatura. Assim sendo, quanto maior essa consciência, maior é seu caráter nacional.

Em 1978, Antonio Cornejo Polar publica na Revista de Crítica Latinoamericana o ensaio intitulado "El indigenismo y las literaturas heterogéneas: su doble estatuto sociocultural", no qual apresenta a categoria de sistema como um método de estudo válido para as literaturas latino-americanas sujeitas a um duplo estatuto sociocultural, isto é, as literaturas heterogêneas. Cornejo Polar questiona o uso pelas historiografias literárias do conceito de nação, chamando a atenção para a autonomia e a homogeneidade que o corpus literário passa a ter sob a perspectiva nacional. Além disso, a categoria nacional é, para o crítico, muito ampla, não permitindo a consideração de aspectos internos.

Antonio Cornejo Polar interessa-se especialmente por aquelas literaturas que manifestam os conflitos ou ambiguidades gerados em função do contato de diferentes culturas na constituição, por exemplo, do sistema que estrutura internamente a literatura latino-americana. A heterogeneidade manifesta-se através de muitas e diferentes formas e níveis, afirma o crítico. Na tríade autor/obra/público ou no sistema formalista de comunicação que considera o emissor, o destinatário, o referente e o código, haveria pelo menos um dos elementos que não coincide com a filiação dos outros. Assim, nas crônicas de viagem, por exemplo, o referente, que seria o Novo Mundo, não pertence à mesma configuração cultural dos demais, o que resulta em uma produção na qual é possível verificar os conflitos consequentes dessa heterogeneidade.

Mas, Antonio Cornejo Polar não explora a categoria de sistema em sua forma original, uma vez que, se tomada ao pé da letra, acabava por não considerar os processos históricos: "É preciso insistir, de qualquer modo, em que sistema sem história é uma abstração ilegítima e enganosa” (1978, p. 11), afirma o crítico. Este seria um ponto em comum, uma 
sintonia entre as abordagens da literatura através da noção de sistema em Antonio Candido e Antonio Cornejo Polar, pois, como já se afirmou, o crítico brasileiro também defendia a importância da consideração das "condições materiais de produção" da literatura para sua análise. Nos dois casos, há uma revisão, uma transformação até certo ponto da metodologia ali implicada. Trata-se da busca por uma teoria autenticamente latino-americana, que leva em consideração a especificidade dos processos históricos da região, uma perspectiva de cunho político que retoma, no caso de Cornejo Polar, os pressupostos de José Carlos Mariátegui e, em Antonio Candido, sua formação sociológica e seu manuseio da dialética hegeliana/marxista.

Por outro lado, os críticos também compartilham um questionamento de certa noção de literatura. Está implicada na noção de sistema literário manuseado por esta tradição crítica a ideia de que a literatura é a expressão de diversos grupos sociais. Alejandro Losada, outro importante professor da Universidad Nacional Mayor de San Marcos nos anos 1970, vê os sistemas literários, a partir dos aportes da teoria lukacsiana, como práxis dos grupos sociais, como a atividade de certos grupos que nela definem sua vida e seu pertencimento ao mundo social. Nesse sentido, "Literatura e subdesenvolvimento", de Antonio Candido, é um exemplo que ilustra, para Losada (1975), tal modelo conceitual. Grosso modo, pode-se portanto afirmar que essa perspectiva crítica rompe com a ênfase no caráter estético, com o olhar apenas para o cultivo da palavra nas composições. Enfim, põe em questão a noção de literatura como "Belas-Artes".

No entanto, Antonio Cornejo Polar ainda realizará efetivamente uma atualização da categoria de heterogeneidade e da própria noção de sistema nela subjacente. Em seu livro Escribir en el aire: ensayo sobre la heterogeneidad sociocultural en las literaturas andinas, de 1994, trata de verificar nas instâncias do processo de configuração dessas literaturas que cruzam de maneira conflituosa dois ou mais universos socioculturais, processosdeheterogeneidadeinternosaelas. Essasinstâncias, inicialmente pensadas nos moldes formalistas, também se atualizam. Sua preocupação em considerar os aspectos históricos colocava em contradição as ideias de estrutura e processo, o que o levou a optar pelo uso do que chamou "três núcleos problemáticos: discurso, sujeito e representação” (CORNEJO POLAR, 2011). De qualquer forma, a referência à variedade literária da região ainda é tratada como sistema, sendo o erudito, o popular e o indígena os mais destacados nos estudos do crítico. 
Não houve uma reavaliação, uma atualização da categoria de sistema dentro da produção intelectual de Antonio Candido, ainda que valha salientar que esta começou muito antes da do crítico peruano. Enquanto Cornejo Polar, nos anos 1990, insistia em seu uso, transformando-a conforme os novos debates que fomentavam a crítica, em 1997, quando Antonio Candido já se encontrava aposentado, foi publicada, pela Universidade de São Paulo (USP), a Iniciação à literatura brasileira, uma espécie de resumo da Formação da literatura brasileira que, de certa forma, atesta a manutenção da perspectiva forjada por Antonio Candido nos anos 1950 como modo de leitura da história literária brasileira.

Mas também éao cotejarmos o funcionamento da dinâmica do sistema nos dois críticos que emerge uma importante diferença. A perspectiva com a qual Antonio Candido maneja a noção de sistema ressalta seu pleno funcionamento, para que esta culmine em literatura. O caso de Gregório de Matos Guerra (século XVII), o "Boca do Inferno", é revelador nesse sentido, uma vez que o autor não foi lido em sua época, sua obra poética só conheceu o formato de livro, conforme Candido, na segunda metade do século XIX; e, especialmente, fica pressuposto que sua produção não atenderia ao critério de "elaboração de uma linguagem própria", já que se utiliza da linguagem barroca espanhola. Assim sendo, a produção de Gregório de Matos Guerra seria uma manifestação literária de nosso país, pois não conforma um sistema, não contribui para a formação de uma tradição literária, para ser chamada de literatura. É a esta perspectiva histórica linear que se refere a querela promovida por Haroldo de Campos (1989), que julgava como "sequestro" a desconsideração do barroco na Formação da literatura brasileira. Já em "Literatura e subdesenvolvimento", o fato de tomar como influências os contatos com a produção cultural estrangeira e a superação da dependência "como a capacidade de produzir obras de primeira ordem, influenciadas, não por modelos estrangeiros imediatos, mas por exemplos nacionais anteriores" (1972, p. 354), reafirma a perspectiva nacional.

O conceito de heterogeneidade, defendido por Cornejo Polar, por outro lado, não toma como critério o perfeito funcionamento do sistema para definir o que é ou não literatura. Outrossim, destaca os conflitos advindos das diferentes culturas que compõem os elementos do sistema, neles estaria a riqueza a ser explorada analiticamente. Sem falar que a categoria de nação foi recorrentemente problematizada por Cornejo Polar, como pode ser observado através de outra categoria importante proposta 
pelo crítico, a de “totalidade contraditória”. Para Patricia D’Allemand, que se dedica ao sistema conceitual do autor,

frente a la visión totalizadora insuficiente y tramposamente mutiladora y homogeneizante hasta entonces hegemónicas en la disciplina, Cornejo aspira ahora a construir una totalidad esta vez fiel a la pluralidad literaria y sociocultural empíricamente verificables, ya sea de la sociedad peruana, o de las sociedades regional o continental, según varíe el objeto al que Cornejo atienda (D'ALLEMAND, 2002, p. 131).

A “totalidade contraditória” se desprende desta revisão da noção de literatura nacional e aponta diretamente para a unidade prevista como contradição. Assim sendo, o nacionalismo, a ênfase na importância de a constituição da literatura se dar internamente no país até conformar uma tradição distanciam a perspectiva de sistema do crítico brasileiro da valorização da heterogeneidade do crítico peruano.

Por outro lado, a utilização da categoria de sistema tal qual pensou Antonio Candido foi tomada de maneira muito fiel por Ángel Rama. Entre o crítico uruguaio e Antonio Candido, pode-se afirmar que a categoria de sistema funciona como um elemento constitutivo de um pensamento comum. Seu estudo sobrea poesiagauchesca, Los gauchipolíticos rioplatenses (1976), utiliza a categoria para demonstrar que a gauchesca é literatura e não manifestação literária.

Pode-se considerar, portanto, que o interesse comum pela categoria de sistema não necessariamenteexpõeumavinculaçãodireta entreopensamento dos críticos. O momento no qual eles mais se aproximam é a década de 1970, década em que foram publicados tanto "Literatura e subdesenvolvimento" como "El indigenismo y las literaturas heterogêneas", textos que, assim como a Formação da literatura brasileira de Antonio Candido, apresentam um manuseio da categoria de sistema mais próximo de sua elaboração formalista. Por outro lado, é também o auge das atividades e debates acerca do integracionismo e do latino-americanismo que enquanto projetos eram comuns aos dois críticos.

O mesmo é possível observar em Hacia una historia de la literatura latinoamericana, que reúne as intervenções da reunião de Caracas (1982) com o propósito de discutir a constituição de uma história da literatura da região. Esse é um projeto que envolve concretamente uma rede de críticos na América Latina e que resulta em um produto específico, que encontra, de certa maneira, suas origens nas Jornadas de literatura latino-americana 
de Campinas (1980).3 A reunião possui algumas apresentações seguidas de debates, e Antonio Candido não figurará como debatedor da apresentação de Cornejo Polar e vice-versa. O crítico peruano voltará a enfatizar em seu texto "La literatura latinoamericana y sus literaturas regionales y nacionales como totalidades contradictorias" a importância na consideração tanto da diversidade cultural do continente como das tensões e conflitos que subjazem sua constituição, elementos estes implicados em seus conceitos de "heterogeneidade" e "totalidade contraditória” já vistos. Já Antonio Candido voltará a enfocar o caráter "empenhado", agora não apenas da literatura brasileira mas da latino-americana de modo geral. E destacará a relevância da "função histórica" pensada como a concomitância do externo e do interno na malha textual: "Que aquello que situaciona la creación del texto, se vuelve el texto mismo”, afirma (1982, p. 181). Trata-se do procedimento crítico de viés sociológico e textual, posto em prática para cumprir com o objetivo de consideração das "condições materiais de produção" do texto literário, já visto aqui como uma preocupação também presente em Cornejo Polar, ainda que seja importante destacar a filiação do pensamento de Candido, nesse caso, à teoria da dependência, o que não acontece com o pensamento de Cornejo Polar.

Mesmo que não haja uma manifestação negativa equeas falas de Antonio Candido contemplem a preocupação e a defesa da diversidade de sistemas literários, é evidente a maior afinidade e identificação com as discussões que incluem a oralidade e a literatura indígena por parte do crítico peruano. Nesse sentido, é reveladora a discussão estabelecida entre Cornejo Polar e Roberto Schwarz, durante o evento, em torno da proeminência do sistema culto em detrimento de outros sistemas literários. Schwarz (1982, p. 132-133) revela que a dinâmica de inclusão dos outros sistemas poderá implicar no rebaixamento

$3 \mathrm{O}$ ponto de partida institucional do projeto de organização da história, que culminou na publicação, nos anos 1990, de América Latina: palavra, literatura e cultura é, de acordo com Ana Pizarro (2013), a Associação Internacional de Literatura Comparada, mas o apoio real para a efetiva concretização aconteceu em São Paulo, por intermédio de Antonio Candido. Em 1983, após já haver sido sediado na Universidad Simón Bolívar (Caracas), o projeto não só possui apoio da Unesco como da própria Unicamp. Dessa maneira, aconteceram nesse ano, novamente em Campinas, eventos que reuniram os três críticos. Um encontro sobre história da literatura latino-americana, em julho e outro em outubro. Do primeiro, tem-se outra entrevista com Ángel Rama e Antonio Cornejo Polar, realizada pelo professor da Unicamp, Carlos Vogt. Já do segundo encontro, foi produzido um livro intitulado La literatura latinoamericana como proceso (1985), no qual o crítico peruano encontra-se citado nas discussões registradas. 
da literatura culta, que possui papel fundamental pois vive sob o "signo da historicidade" buscando nova interpretação. Enquanto que Cornejo Polar (1982, p. 133-134) procurará mostrar que não se trata de um rebaixamento e sim de evitar a proeminência do sistema culto, possibilitando a consideração dos outros sistemas que podem ser, em termos quantitativos, mais representativos do que o sistema culto, em determinadas regiões.

Outro importante lugar de aproximação entre Antonio Cornejo Polar e Antonio Candido é, no Peru, a Revista de Crítica Literaria Latinoamericana, doravante RCLL. A revista é criada em Lima, em 1973, a partir das discussões sobre teorias da literatura latino-americana auspiciadas pela Universidad Nacional Mayor de San Marcos edirigidas pelo professor Antonio Cornejo Polar. Surge como uma alternativa de crítica própria, voltada para o contexto cultural e social, buscando ajustar-se à especificidade das literaturas latino-americanas. A revista, conforme informações de seu site, foi fundada também para acompanhar com material crítico a revista de teoria Problemas de Literatura, fundada um ano antes em Valparaíso, por Nelson Osorio e Helmy Giacoman. Esta seria retirada de circulação no final daquele ano pela ditadura militar e o projeto da revista peruana teve que assumir parte da agenda cancelada no Chile. Com esse perfil, sai, em outubro de 1975, o primeiro número e inclui textos que gravitariam notavelmente em torno do latino-americanismo posterior: Algunos problemas teóricos de la literatura hispanoamericana, de Roberto Fernández Retamar, e Los sistemas literarios como instituciones sociales en América Latina, de Alejandro Losada. É, desde 2012, auspiciada pela Universidade de Tufts, em Boston (EUA).

Antonio Candido é membro do Conselho Editorial da revista desde o segundo semestre de 1979 até os dias atuais e possui apenas dois ensaios publicados no periódico: "Conhecer, conviver, integrar: anotações muito pessoais”, de 1999, no qual relata brevemente suas aproximações à América Hispânica e homenageia Antonio Cornejo Polar; e "O papel do Brasil na nova narrativa”, que aparece no segundo semestre de 1981. A presença de artigos sobre a literatura brasileira ${ }^{4}$ é recorrente, mas, entre 1980 e 1983, observa-se

${ }^{4}$ Na década de 1970, encontram-se apenas três textos sobre literatura brasileira: uma resenha de Luis Fernando Vidal sobre a Antología de la poesía brasileña, de Ángel Crespo (1976); a apresentação da bibliografia de Carlos Drummond de Andrade, por José Paulo Netto, também de 1976; e o ensaio da diretora de teatro e atualmente professora da PUC-Perú, a peruana Alicia Saco: "De la ilusión a la reflexión, de la reflexión a la acción: en torno a las nuevas técnicas teatrales de Augusto Boal” (1975). Já em 1986 são publicados "El gusto por lo brasileño: antropología y literatura en Gilberto Freyre y Darcy Ribeiro", de Ulrich Fleischmann, e "A nossa vendeia: Canudos, o mito da Revolução Francesa e a constituição da identidade nacional cultural no Brasil [1897-1902]”, de Roberto Ventura. 
um aparecimento mais frequente do tema. Além de Antonio Candido, entre os colaboradores brasileiros, tem-se apenas, durante esse período, a participação de Carlos Alberto Azevedo, com o texto "Literatura \& práxis social no Brasil: o romance nordestino de 1930" (1983), e a de Ferreira Gullar, que resenha o livro de Ángel Nuñez, Narraciones del destierro, de 1980. No entanto, observam-se outros artigos sobre a literatura brasileira: o livro $O$ tupi e o alaúde, de Gilda de Mello e Souza (esposa de Antonio Candido), é resenhado pelo escritor e crítico peruano Luis Fernando Vidal. Este é também autor, nesse período, de "Algunas reflexiones sobre la cuentístisca de Machado de Assis", publicado na RCLL, em 1982. Um ensaio longo e de mais fôlego que os demais textos sobre literatura brasileira desses anos é "Aluisio Azevedo y el naturalismo en Brasil" (1981), do chileno, atualmente professor da Universidade de Oregon, Juan Armando Epple. Acompanha o artigo, no mesmo número da revista, a "Bibliografía de Aluisio Azevedo", organizada por Epple. Mas, o mais sintomático número em termos de comparatismo durante a década de 1980 é o 15, de 1982. Trata-se de número monográfico sobre as vanguardas na América Latina que apresenta textos mais abrangentes sobre o vanguardismo latino-americano ou textos que tratam especificamente de um autor vanguardista ou a vanguarda em um dos países, como o de Márgara Russotto sobre os manifestos do Modernismo brasileiro.

"O papel do Brasil na nova narrativa" (1981), de Antonio Candido, inicia com um relevante comentário sobre como são comuns referências à América Latina que não incluem o Brasil e, logo depois, faz um levantamento dos traços comuns, não das literaturas ibéricas da região, mas de aspectos históricos, sociais e culturais gerais presentes nos países do continente. Esta primeira e curta parte do texto termina com citações de Rubem Fonseca e de Roberto Drumond, que, de forma contraditória, satiriza a existência de uma literatura latino-americana - o primeiro - ou acredita não só em sua existência, mas em sua força - o segundo. Porém chama a atenção a continuidade do texto, ou melhor, seu desenvolvimento, pois se espera que, ao tratar do papel do Brasil na nova narrativa, sendo esta a nova narrativa latino-americana ainda em seu auge nos anos 1980, encontre-se um paralelo, um quadro comparativo ou aproximações da literatura de nosso país às hispano-americanas. Sabe-se que a expressão "nova narrativa” não designa um corpo uniforme, mas as tendências da nova narrativa brasileira apontadas pelo autor também não configuram um único estilo, projeto. Ainda que Candido tente demonstrar o quanto ela é fruto, seja dando continuidade a eles ou contrariando-os, de seus 
antecessores imediatos dos anos de 1930 e 1940, deixa claro seu caráter multifacetado. Desse modo, além de não cumprir com o que se espera do texto a partir do que indica o título, também não expõe aquela visão de conjunto, a mesma que ele afirma no mesmo texto ser possível de ser realizada:

[...] no passado e no presente, muitos elementos comuns permitem refletir sobre a cultura e a literatura da América Latina como "um conjunto". Parafraseando Mário de Andrade - sobre o tronco dos idiomas ibéricos a anamorfose imperialista criou vinte orquídeas sangrentas, desiguais entre si, mas sobretudo em relação a ele (CANDIDO, 1981, p. 105).

De maneira geral, o mesmo pode ser dito sobre a presença do Brasil na $R C L L$, naquele momento. Especialmente, no que concerne a discussões conjuntas de produções brasileiras e produções hispano-americanas, na medida em que tratam especificamente de autores ou temas de nosso país não considerando uma perspectiva comparatista. Há, portanto, na revista, um esforço para a aglutinação das discussões sobre a literatura brasileira, inclusive a partir da perspectiva de pesquisadores hispano-americanos; no entanto, o estabelecimento de um diálogo parece concluir-se na presença do Brasil na revista e não em discussões que passem necessariamente pelos contatos, trânsitos e/ou contágios existentes entre a literatura da região. ${ }^{5}$

Antonio Cornejo Polar (1987, p. 67-68) já perguntava nas discussões em Caracas qual seria a perspectiva prevalecente no projeto de construção da história da literatura latino-americana que, naquele momento, passa a integrar o programa da Associação Internacional de Literatura Comparada (AILC). O crítico pede esclarecimentos a partir da apresentação de Franco Meregali, "La perspectiva comparatista", já que estaria entendendo o projeto como a construção de uma história social da literatura latino-americana e não como uma história comparada. No mesmo debate, ainda que não esteja respondendo diretamente a Cornejo Polar, Antonio Candido ressalta a importância do comparatismo, inclusive do comparatismo contrastivo para a consideração do caso brasileiro dentro da unidade latino-americana. Ainda que se possa ler nas bases dos textos e projetos

5 Terão que passar alguns anos para que o comparatismo apareça na revista em seção monográfica. O número 45, do primeiro semestre de 1997, apresenta dossiê sobre o diálogo entre Brasil e América Hispânica, com textos de, entre outros críticos, Raúl Antelo e João Adolfo Hansen. 
anteriores certo comparatismo, os registros da reunião em Caracas revelam que, para essa "crítica latino-americana", discutir a integração da região e/ou a constituição de um pensamento latino-americanista via literatura (teoria, crítica e história) não implica, necessariamente, trabalhar ou aplicar o comparatismo. Ele foi incorporado, de maneira fundamental, a essas discussões a partir do momento em que ocorre a inserção do projeto de construção da história literária, por Ana Pizarro, na AILC.

Trata-se de mais um importante aspecto que demonstra as diferentes perspectivas teóricas em discussão no interior do projeto. $\mathrm{O}$ interesse em dar à crítica, à teoria e/ou à história literárias latino-americanas bases teóricas articuladas à realidade da região e às exigências contemporâneas põe em evidência (assim como quando se unem as literaturas) o desafio de lidar também com uma diversidade de pensamentos e de propostas teóricas, ainda que seja entre aqueles que se juntam em torno de um mesmo projeto. Antonio Cornejo Polar (2013, p. 8) reconhece o fracasso do projeto, já que não se tem a desejada teoria literária latino-americana, mas afirma ser justamente na forma de lidar com a "escurridiza", "multi y transcultural" literatura de nossa região que se encontram as principais contribuições desse projeto.

\section{REFERÊNCIAS BIBLIOGRÁFICAS}

AGAMBEN, Giorgio. O que é um dispositivo. In: O que é o contemporâneo? e outros ensaios. Chapecó: Argos, 2009, p. 25-51.

CAMPOS, Haroldo de. O sequestro do Barroco na Formação da literatura brasileira. Salvador: Fundação Casa de Jorge Amado, 1989.

CANDIDO, Antonio. O papel do Brasil na nova narrativa. Revista de Crítica Literaria Latinoamericana, Lima: Latinoamericana Editores, n. 14, p. 103-117, segundo semestre de 1981.

CANDIDO, Antonio. A experiência hispano-americana de Antonio Candido. Entrevista a Pablo Rocca. Literatura e Sociedade, São Paulo, n. 12, 2009. Disponível em: http:// www.revistas.usp.br/ls/article/view/25197. Acesso em: 22 jun. 2015.

CANDIDO, Antonio. Iniciação à literatura brasileira. 3. ed. São Paulo: Humanitas, 1999.

CANDIDO, Antonio. Literatura e subdesenvolvimento. In: América Latina em sua literatura (coord.: César Fernández Moreno). São Paulo: Perspectiva, 1972, p. 343-362. 
64 - Remate de Males 36.1

CORNEJO POLAR, Antonio. El indigenismo y las literaturas heterogéneas: su doble estatuto sociocultural. Revista de Crítica Literaria Latinoamericana, Lima: Latinoamericana Editores, n. 7-8, p. 7-21, segundo semestre de 1978.

CORNEJO POLAR, Antonio. Escribir en el aire: ensayo sobre la heterogeneidad sociocultural en las literaturas andinas. Lima: Centro de Estudios Literarios "Antonio Cornejo Polar" (CELACP); Latinoamericana Editores, 2013.

LOSADA, Alejandro. Los sistemas literarios como instituciones sociales en América Latina. Revista de Crítica Literaria Latinoamericana, Lima: Latinoamericana Editores, ano 1, n. 1. p. 39-6o, 1975 .

MAÍZ, Claudio. Entrevista con Ana Pizarro: las redes de la crítica literaria y la gestación del proyecto de una historia de la literatura latinoamericana. CILHA, Mendoza, Argentina, ano 14, n. 17, 2013.

OSORIO TEJEDA, Nelson. Prólogo. Antonio Cornejo Polar y la nueva crítica literaria latinoamericana. In: CORNEJO POLAR, Antonio. Sobre literatura y crítica latinoamericanas. 2. ed. Lima: Centro de Estudios Literarios "Antonio Cornejo Polar" (CELACP); Latinoamericana Editores, 2013, p. 9-20.

PIZARRO, Ana (coord.). Hacia una historia de la literatura latinoamericana. México: Universidad Simón Bolívar; El Colegio de México, 1987.

RAMA, Ángel. Los gauchipolíticos rioplatenses. Buenos Aires: Centro Editor de América Latina, 1993.

SARLO, Beatriz. La literatura de América Latina: unidad y conflicto. Punto de Vista, Buenos Aires, n. 8, p. 3-9, mar.-jun. 1980. 